The University of Maine

\title{
DigitalCommons@UMaine
}

Maine-Syracuse Longitudinal Papers

Maine-Syracuse Longitudinal Study

2012

\section{Relation between dairy food intake and cognitive function: The Maine-Syracuse Longitudinal Study}

Georgina E. Crichton

University of South Australia

Merrill F. Elias

University of Maine, mfelias@maine.edu

Gregory A. Dore

University of Maine

Michael A. Robbins

University of Maine, michael.robbins@umit.maine.edu

Follow this and additional works at: https://digitalcommons.library.umaine.edu/ longitudinal_papers

\section{Repository Citation}

Crichton, Georgina E.; Elias, Merrill F.; Dore, Gregory A.; and Robbins, Michael A., "Relation between dairy food intake and cognitive function: The Maine-Syracuse Longitudinal Study" (2012). Maine-Syracuse Longitudinal Papers. 42.

https://digitalcommons.library.umaine.edu/longitudinal_papers/42 


\title{
Relation between dairy food intake and cognitive function: The Maine-Syracuse Longitudinal Study
}

\author{
G.E. Crichton ${ }^{a,}{ }^{,}$, M.F. Elias ${ }^{b, c}$, G.A. Dore ${ }^{b}$, and M.A. Robbins ${ }^{b, c}$ \\ a Nutritional Physiology Research Centre, University of South Australia, Adelaide 5001, Australia \\ b Department of Psychology, University of Maine, Orono, ME, USA \\ ${ }^{c}$ Graduate School of Biomedical Sciences, University of Maine, Orono, ME, USA
}

\section{Abstract}

\begin{abstract}
Diet modification to alter the course of age-related cognitive decline is becoming increasingly important. Few observational findings suggest that dairy food intake may be positively related to cognitive function, but research in this novel area is limited. The aim of this study was to investigate whether dairy food intake is associated with cognitive function, before and after adjustment for cardiovascular, lifestyle and dietary factors. To do this, a cross-sectional analyses of a subset of the community-based Maine-Syracuse Longitudinal Study (MSLS) sample ( $N=$ 972) was undertaken. It was determined that participants who consumed dairy products at least once per day had significantly higher scores on multiple domains of cognitive function compared with those who never or rarely consumed dairy foods, adjusting for cardiovascular risk factors, lifestyle and dietary factors. Frequent dairy food intake is associated with better cognitive performance but underlying causal mechanisms are still to be determined.
\end{abstract}

\section{Introduction}

As the population ages, cognitive decrement and dementia, are not only of great burden to sufferers and their families, but place increasing strain on the health care system. Moreover, decrements in cognition in non-demented individuals represent a risk factor for the development of dementia later in life (Elias et al., 2000). Easily implemented lifestyle changes that individuals can make present an opportunity to slow or prevent neuropsychological dysfunction.

Diet modification is one such change that may ultimately aid in the prevention of age-related cognitive impairment and decline (Bryan, 2004; Solfrizzi, Panza, \& Capurso, 2003). Dairy foods are one component of the diet that have received little attention in relation to cognition, despite accumulating evidence that these foods may be of benefit to cardiovascular health. Dairy food consumption may have advantageous effects on body weight (Major et al., 2008; Zemel, 2005; Zemel et al., 2009), blood pressure (Azadbakht, Mirmiran, Esmaillzadeh, Azizi, \& Azizi, 2005b; Steffen et al., 2005; Wang, Manson, Buring, Lee, \& Sesso, 2008), type 2 diabetes (Choi, Willett, Stampfer, Rimm, \& Hu, 2005; Liu et al., 2006) and the metabolic syndrome (Azadbakht, Mirmiran, Esmaillzadeh, \& Azizi, 2005a; Azadbakht et al., 2005b; Elwood, Pickering, \& Fehily, 2007; Lutsey, Steffen, \& Stevens, 2008; Mennen et al., 2000; Pereira et al., 2002), all of which are cardiovascular disease (CVD) risk factors that increase the likelihood of cognitive dysfunction (Waldstein

\footnotetext{
(C) 2011 Elsevier Ltd. All rights reserved.

*Corresponding author. Tel.: +61 88302 1452; fax: +61 88302 2178. whige003@mymail.unisa.edu.au (G.E. Crichton)..
} 
\& Elias, 2001). Imparting beneficial change in cardiometabolic health may therefore be the primary mechanism by which dairy foods reduce the risk for cognitive decline.

The literature in this novel area to date consists of a small collection of observational studies where relationships between dairy food intakes and cognition have not been the primary focus. Our recent systematic review of the literature (Crichton, Bryan, Murphy, \& Buckley, 2010a) identified eight observational studies that have reported on associations between dairy food intake and cognitive function (Almeida, Norman, Hankey, Jamrozik, \& Flicker, 2006; Avila-Funes, Garant, \& Aguilar-Navarro, 2006; Eskelinen et al., 2008; Laitinen et al., 2006; Lee et al., 2001; Rahman, Sawyer Baker, Allman, \& Zamrini, 2007; Vercambre, Boutron-Ruault, Ritchie, Clavel-Chapelon, \& Berr, 2009; Yamada et al., 2003). The findings have been consistent and suggest some benefit from the consumption of dairy food. Greater intakes of milk or dairy products have been associated with better general cognitive function (Lee et al., 2001), and decreased likelihood for vascular dementia (Yamada et al., 2003) and cognitive impairment (Rahman et al., 2007). In contrast, the consumption of whole-fat dairy products may be associated with poorer cognitive function in the elderly (Almeida et al., 2006; Eskelinen et al., 2008; Laitinen et al., 2006; Vercambre et al., 2009).

Despite the small number of studies investigating relationships between dairy food intake and cognition, the findings have been consistent and support a previous cross-sectional study in a community-based sample of over 1000 Australian adults (Crichton, Murphy, \& Bryan, 2010b). In this study, low fat yoghurt intake was positively associated with memory recall and social functioning in men, while low fat cheese intake was positively associated with social functioning and negatively associated with stress in women. The consumption of whole-fat dairy products, including ice-cream and cream, were associated with higher levels of self-reported anxiety, stress, and depressed mood, and poorer memory functioning. However, cognitive performance and psychological well-being were assessed via selfreported measures; neuropsychological testing was not conducted. A review of the literature on dairy products and cognitive function indicates a need for studies on cognitive performance and dairy consumption in community-based samples which take into account more variables that may confound relations between dairy product consumption and cognition (Crichton et al., 2010a).

In the present study we examine relations between dairy food intake and cognitive function in a community-based, dementia-free population. We expand upon the current literature by utilizing a thorough, standardized neuropsychological test battery to assess cognitive performance in adults across the life span. Additionally, we examine these relationships before and after adjustment for CVD risk factors, dietary and lifestyle variables that impact upon cognition. We hypothesize that those with higher intakes of dairy products will have better cognitive outcomes, and that the magnitude of these relations will be attenuated by the addition of CVD, lifestyle or dietary factors.

\section{Methods}

\subsection{Participants}

Participants were obtained from the Maine-Syracuse Longitudinal Study (MSLS), a community-based study of CVD risk factors and cognitive functioning in adults (Dore, Elias, Robbins, Budge, \& Elias, 2008; Elias et al., 2006, 2009b; Robbins, Elias, Elias, \& Budge, 2005). The MSLS consists of five cohorts defined by time of entry into the study (1975-2000). At initial recruitment, participants were living independently in Syracuse, NY, and surrounding communities within driving or public transportation distance of the study laboratory, and were recruited for studies of blood pressure and cognition from public advertisements in the local print media, flyers and posters, and presentations of the project to 
civic groups and churches. The only exclusions at recruitment were diagnosis or treatment for psychiatric illness, alcoholism, and inability to read and see sufficiently to comprehend instruction, or comply physically with required testing procedures.

Data were collected from self-report (paper and pencil inventories) medical examinations, diagnostic interviews, health records, and neuropsychological testing. The data for the present study were taken from subjects returning for the sixth (2001-2006) study wave as dietary intake measures were first obtained at this examination. The MSLS was approved by the University of Maine Institutional Review Board, and informed consent for data collection and medical record review was obtained from all participants. This specific use of the de-identified MSLS data was also approved by the University of South Australia Human Ethics Committee.

Beginning with a sample of 1049 individuals, participants were excluded for the following reasons: missing dietary or cognitive data $(n=34)$, acute stroke $(n=28)$, probable dementia $(n=8)$, undertaking dialysis treatment $(n=5)$, inability to read English $(n=1)$, and prior alcohol abuse $(n=1)$, leaving 972 participants. Dementia cases were excluded due to the few numbers and the dramatic influence on cognition. We were interested in examining relationships between diet and cognitive performance, but not in those with severe cognitive impairment. The clinical diagnosis of dementia was determined by committee using the National Institute of Neurological and Communicative Diseases and Stroke/Alzheimer's Disease and Related Disorders Association (NINCDS-ADRDA), using MSLS cognition data, diagnostic records, and medical interview data (McKhann et al., 1984). Stroke was defined as a focal neurological deficit of acute onset persisting for more than $24 \mathrm{~h}$, was based on self-report or medical records, confirmed by hospitalization, record review or both. The final sample with complete wave 6 data for cross-sectional analyses comprised 399 males and 573 females, aged 23-98 years.

\subsection{Procedure and assessment}

Participants completed the Centre for Epidemiologic Studies Depression Scale (CES-D) (Radloff, 1977), the Nurses' Health Study Activity Questionnaire (Wolf et al., 1994), and the Nutrition and Health Questionnaire (Kaaks \& Riboli, 1997) within two weeks prior to their laboratory visit. At this visit, all questionnaires were checked for completion and for any updates, corrections or changes the participant wished to make. Participants then underwent a blood draw by a licensed phlebotomist, following an overnight fast. Our standard assay methods have been previously described (Elias et al., 2006, 2008). After a light breakfast, including decaffeinated tea or coffee, participants underwent a physical examination (measures of activity, walking, standing, turning), cognitive testing and medical interview. Automated blood pressure measures (GE DINAMAP 100DPC-120XEN, GE Healthcare) were taken five times each in reclining, sitting and standing after a supine rest for $15 \mathrm{~min}$, with a five minute rest between each set of measures. Hypertension was defined as blood pressure $\geq 140 / 90$ or treated for hypertension. Waist circumference (in centimetres) was taken over light clothing, using a non-extendable measuring tape, at the level of the iliac crest. Prevalent CVD was based upon self-reported history of coronary artery disease, myocardial infarction, congestive heart failure, transient ischaemic attack, or angina pectoris, confirmed by medical records.

2.2.1. Cognitive function-The MSLS neuropsychological test battery has been used in numerous studies assessing health variables and cognition (Dore et al., 2008; Elias et al., 2006, 2009a, 2009b; Robbins et al., 2005). The dependent variables in this study were the following composite scores: Visual-Spatial Memory and Organization composite, Scanning and Tracking composite, Verbal Episodic Memory composite, Working Memory composite, 
Executive Function composite, Global composite and the following individual tests:

Similarities, a measure of abstract reasoning (Lezak, Howieson, \& Loring, 2004), and the MMSE (Mini-Mental State Examination). The derivation of these composites has been described previously (Elias et al., 2006) and they have been repeatedly utilized in MSLS studies. The MMSE (Folstein, Folstein, \& McHugh, 1975), a global measure of mental status was added because of its wide use in the literature. Table 1 summarizes the tests used to define each composite and the latent variables measured. Following the MSLS protocol (Elias et al., 2009b), raw test scores making up the composites were transformed to $z$-scores, added, and re-standardized, resulting in a mean of zero and a standard deviation (SD) of 1.00 for each test and enabling all performance measures to be expressed in the same unit of measurement (SD units). The composite score was also expressed in $z$-score units.

2.2.2. Dietary intake — The Nutrition and Health Questionnaire (Kaaks \& Riboli, 1997) was designed for use in the European Prospective Investigation into Cancer (EPIC) (Kaaks \& Riboli, 1997; Riboli \& Kaaks, 1997). There are 41 questions about dietary intake and lifestyle, including smoking history, physical activity (at work, home, and recreational), living situation, marital status, medical history, self-reported health, and medication and supplement use.

The first one-half of the questionnaire forms the dietary component. It questions participants about their frequency of consumption of meat, fish, dairy products, eggs, breads, cereals, and beverages including tea, coffee, carbonated drinks, water, fruit juice, and alcohol. A list of 37 foods follows, including fruit and vegetables, rice and pasta, dairy foods, meats and fish, chocolate, nuts, and other snack-type foods. Participants were required to stipulate how frequently they consume each food, with six response options: never, seldom, once a week, 2-3 times a week, 5-6 times a week or once or more a day. Dairy products included were milk, cheese, yoghurt and dairy desserts (grouped together), ice-cream and cream (grouped together), and total dairy foods. Milk was the only dairy food for which participants were asked to stipulate the type consumed in terms of fat content (whole fat, reduced fat, skim).

The median score within each response option was used to estimate total intakes per week; for example, 2-3 times per week was estimated at 2.5. The mean number of times each food was consumed on a weekly and then daily basis was calculated for all foods in the questionnaire. As portion sizes were not stipulated to participants, these totals are an estimate of the number of times each food was consumed on a daily basis. Individual foods were categorized into five major food groups (in addition to dairy products) - grains, fruits, vegetables, protein foods, and fats/sweets/other - based on the USDA Food Guide Pyramid (United States Department of Agriculture, 2011). Intakes of individual foods and beverages within each food group were summed to give an estimate of total intake for each group. An estimation of total energy intake was calculated by adding intakes of all food groups, and was used to control for energy intake in subsequent analyses. The primary predictor variable in this study was total dairy food consumption.

\subsection{Statistical analyses}

Data were analyzed with SPSS (Version 18, Chicago, IL, USA). Preliminary analyses involved a comparison between participants who consume dairy products at least once per day and participants who consume dairy products less frequently with respect to demographic and health characteristics. $T$-tests were used to conduct most of these comparisons of demographic and health characteristics. Chi-square tests were used to test differences with regard to prevalent CVD, diabetes, hypertension, metabolic syndrome, and medication use. Analysis of covariance (ANCOVA) was used to compare dietary intakes between the groups, controlling for energy intake by including this as a covariate. 
For the primary analysis, univariate ANCOVA with polynomial trend analyses was used to compare cognitive outcomes across increasing intakes of dairy food consumption, ranging from never/seldom, to at least once per day. Total dairy food intake, and intakes of individual dairy foods (milk, cheese, yoghurt and dairy desserts, cream and ice-cream), were examined in relation to each measure of cognitive performance. As we are interested in the relationship between dairy intake and cognitive performance, all covariates included in the analyses were significantly related to dairy intake and cognitive outcomes. The covariates included were organized into two models: (1) basic set: included age, gender, and education, and (2) cardiovascular/lifestyle/dietary set: included variables in the basic set plus prevalent CVD (yes/no), hypertension (yes/no), waist circumference (cm), self-reported smoking behaviour (cigarettes smoked per week), alcohol consumption (grams per week), depressive symptoms (CES-D raw score), serum folate $\left(\mathrm{ng} \mathrm{dL}^{-1}\right)$, plasma homocysteine $\left(\mu \mathrm{mol} \mathrm{L}{ }^{-1}\right.$ ), and estimated energy intake (total daily intakes of all food groups as previously described). As males had a significantly higher total energy intake than females, this was included in the extended model to control for overall dietary intake. Analyses were adjusted in a sequential manner for the basic and cardiovascular/lifestyle/dietary covariate sets. The variables within each model were entered simultaneously and all possible contrasts were performed between dairy food intake categories. Adjustment for multiple comparisons among treatment groups were made using the SPSS Bonferroni test and adjusted $p$ values are given (alpha $=.05$ / number of contrasts). Moreover, omnibus tests of differences among treatment groups, linear and quadratic trends, were done prior to contrasts between specific groups. With respect to multiple contrasts involving dependent variables, the composite score involving all measures was significant in all cases where further analyses were done using individual composite scores or test measures.

Multivariable logistic regression analyses (SPSS) were undertaken to determine odds ratios associated with performing in the lowest quartile of cognitive scores across categories of dairy food intake, with the lowest category (never/seldom eat dairy food) as the reference group. The same covariate models were used in these analyses.

\section{Results}

Table 2 describes the self-reported frequency of consumption of milk, cheese, yoghurt and dairy desserts, cream and ice-cream, and total dairy food. Over one-third of the sample (37.4\%) reported eating dairy food at least once per day. Slightly over half of the sample $(52.5 \%)$ reported eating dairy foods between two and six times per week. The remaining participants $(10.1 \%)$ reported eating dairy foods no more than once per week. For individual foods, cheese was most often consumed between two and four times per week. Yoghurt, dairy desserts, cream and ice-cream were consumed infrequently, with approximately half of participants never or rarely consuming these foods. Milk intake included milk on cereal and in other beverages such as tea and coffee. Nearly one-third of the sample reported drinking at least $600 \mathrm{~mL}$ of milk on a daily basis, which based on a $250 \mathrm{~mL}$ serve, represents just over two serves per day. A similar proportion of the sample consumed less than $150 \mathrm{~mL}$ day $^{-1}$, with the remaining participants (39.6\%) drinking between 150 and $450 \mathrm{~mL} \mathrm{day}^{-1}$. Of those that drank milk, the majority reported drinking skim or reduced fat milk $(80 \%)$.

Table 3 compares the demographic and health characteristics, and dietary intakes, of participants who reported consuming dairy food at least once per day (37.4\%), with those who consume dairy less frequently than this $(62.6 \%)$. Those who reported consuming dairy food at least daily had a slightly higher number of years of education, smoked less and had a smaller mean waist circumference compared with those who did not consume dairy food on a daily basis (all $p<.05$ ). The less frequent consumers of dairy products had a significantly greater number of depressive symptoms, lower folic acid levels, higher homocysteine 
concentrations, and more prevalent CVD and hypertension. Controlling for total intake from the major food groups (grains, fruit, vegetables, protein foods, other/fats/sweets), those who consumed dairy food on a daily basis ate significantly more vegetables, but consumed fewer grains, fats or sweets, and alcohol.

Associations between cognitive performance across increasing intakes of dairy food are displayed in Table 4. As can be seen, a significant linear trend for cognitive outcome scores was observed across increasing dairy food intake groups for all eight cognitive measures in the basic model (quadratic trend not significant). The highest scores for all eight cognitive outcomes were observed for the highest dairy product consumers. Fig. 1 shows this linear increase in scores across increasing dairy food intake categories for the Global Composite and MMSE scores (basic model). With the addition of cardiovascular, lifestyle and dietary factors, the significant linear trend remained for all outcome measures with the exception of the Executive Function composite. Contrasts performed between categories of intake showed those who consumed dairy foods at least five to six times per week or daily, had significantly higher scores on the Global and Visual-Spatial Memory and Organization composites than those who never/seldom ate dairy foods, or ate dairy foods once per week. The highest two intake groups also performed significantly better on Verbal Memory and Similarities compared with those who ate dairy foods once per week, and had higher MMSE scores than those who never/seldom ate dairy foods (basic model). Daily consumers of dairy foods also performed significantly better than those who ate dairy foods only once per week on the Executive Function and Scanning and Tracking composites.

Significant differences were also observed between moderate and low dairy food consumers. Those who reported eating dairy foods on between two and four occasions per week performed significantly better than those who ate dairy foods once per week on the Global and Visual-Spatial Memory and Organization composite, and the Similarities test, and significantly better on the MMSE compared with those who never/rarely ate dairy foods.

In the extended model, the significant differences observed between moderate to high dairy food consumers with those who consumed dairy food infrequently remained, with the exception of Executive Function. Those who consumed dairy food at least daily had significantly higher scores than those who either never or rarely consumed dairy food (for Global, Visual-Spatial Memory and Organization, and MMSE), or ate dairy food once per week (Verbal Memory, Scanning and Tracking, Similarities). The results show that daily consumers of dairy products had scores of up to .5 SDs higher than the lowest consumers (extended models).

There were no significant associations found between increasing intake categories for specific dairy foods (milk, cheese, yoghurt and dairy desserts, cream and ice-cream) and cognitive outcomes. Those who drank skim or reduced fat milk ( $75.8 \%$ of total sample) had significantly higher scores on the Similarities test and the MMSE than drinkers of whole-fat milk (6.7\% of total sample; $p<.01)$, but this difference was no longer statistically significant after controlling for age, education and gender.

Table 5 summarizes the results from the logistic regression analyses. Those who consumed dairy foods at least daily exhibited significantly lower odds ratios of performing in the lowest quartile of scores on the Global, Visual-Spatial Memory and Organization, Working Memory, and Executive Function composites, the Similarities test, and the MMSE, even after adjustment for demographics, cardiovascular risk factors, lifestyle and dietary factors. Odds ratios for poor performance on the Global, Working Memory, and Executive Function composites, the Similarities test and the MMSE were also significantly lower for those who 
consumed dairy foods at a minimum of twice per week, compared with those who never or rarely ate dairy food.

\section{Discussion}

Dairy product intake was positively associated with cognitive performance across a range of cognitive domains in this dementia-free, community-dwelling population. With adjustment for demographic, cardiovascular, lifestyle and dietary factors, cognitive performance scores increased linearly across increasing categorical levels of dairy food intake for seven out of eight outcome measures. These results, together with findings from other observational studies (Crichton et al., 2010b; Lee et al., 2001; Rahman et al., 2007; Yamada et al., 2003), support an association between high dairy food consumption and cognitive function.

The overall intakes of dairy food in this sample were low. According to self-reported intakes, $62.6 \%$ of the sample did not consume dairy food on a daily basis. Approximately $10 \%$ reported consuming dairy food no more than once per week. These people are therefore not meeting the current recommended daily intakes of two to three servings of dairy products per day (United States Department of Agriculture, 2011). These low consumption patterns are consistent with intakes in other parts of the world. In the United Kingdom, milk consumption has fallen by $33 \%$ over the past 25 years (Elwood, 2005), while a recent study of Australian adults found that $78 \%$ did not meet the Australian Dietary Guidelines recommendation of two to three serves of dairy foods per day (Crichton et al., 2010b).

In the United States, the decrease in milk consumption (Beydoun et al., 2008) has coincided with a dramatic increase in soft drink consumption (French, Lin, \& Guthrie, 2003; Harnack, Stang, \& Story, 1999; Rampersaud, Bailey, \& Kauwell, 2003), with soft drinks being the single largest contributor to energy intake in the US population during the last decade (Block, 2004). Children and adolescents who consume the most soft drink have been shown to consume less milk ( 8 ounces or $237 \mathrm{~mL}$, equating to less than one serve) per day, compared with non-consumers of soft drink (Harnack et al.,1999). This shift in dietary patterns is alarming with regard to the quantity of energy consumed, risk for excess weight gain and obesity, and inadequate nutrient intake.

Consistent with this dietary pattern in children, our data in an adult population suggests that low dairy food consumers may engage in other less healthy lifestyle and dietary habits, and that this is one possible explanation of their poorer performance aside from missing the positive aspects of dairy food consumption. The group of participants who never or seldom ate dairy food in this sample consumed more alcohol, and ate significantly fewer vegetables than those who ate dairy on a daily basis. The lowest dairy food consumers consumed more fats/sweets, but they did not differ from the highest dairy food consumers with respect to plasma levels of high-density lipoprotein (HDL) cholesterol, low-density lipoprotein (LDL) cholesterol, or total cholesterol. There was no evidence suggesting protein deficiency associated with vegan practices in those who did not consume dairy food as this group consumed meat, chicken, eggs and fish in the same amounts as did participants who fell in the other dairy food intake categories. With regard to lifestyle factors, the highest dairy food consumers smoked significantly less than their low dairy counterparts, and self-reported more physical activity. It may the collective effect of an unhealthy lifestyle and poor diet which is having a negative influence on cognitive performance in those with minimal dairy product intakes. Statistically significant differences in these lifestyle and dietary habits were adjusted for in the various regression analyses performed.

The accumulated impact of multiple factors, including lifestyle and dietary choices, are reflected in cross-sectional data up to that point in time. However, little is known from the 
literature about how dairy foods may influence cognition. One possibility is that dairy food consumption may benefit cognitive status via its favourable effect on cardiovascular risk factors linked with increased probability of cognitive impairment. Obesity, type 2 diabetes, hypertension, and dyslipidemia have been frequently associated with poorer performance across a range of cognitive abilities (Dore et al., 2008; Elias, Elias, Sullivan, Wolf, \& D'Agostino, 2003, 2005; van den Berg, Kloppenborg, Kessels, Kappelle, \& Biessels, 2009). Pathological changes in the brain, e.g., white matter lesions, associated with these vascular disease states are also common to cognitive impairment (Akisaki et al., 2006; Breteler et al., 1994; Rabbitt et al., 2007; Soderlund et al., 2006; Tiehuis et al., 2008; Verdelho et al., 2007; Wright et al., 2008).

Evidence for a beneficial effect on weight and fat reduction by calcium and dairy foods (Teegarden, 2005; Zemel, 2004, 2005; Zemel et al., 2009) has been provided in epidemiological studies, animal studies and a small number of randomized trials. This beneficial effect may be assisted by bioactive compounds derived from whey protein in dairy foods (Luhovyy, Akhavan, \& Anderson, 2007; Teegarden, 2005; Zemel, 2004, 2005). Vitamin D in dairy may improve insulin sensitivity and glucose homeostasis through its role in the regulation of calcium homeostasis (Teegarden \& Donkin, 2009; von Hurst,

Stonehouse, \& Coad, 2010). Phosphorus and magnesium may play a role in blood pressure regulation (Alonso et al., 2010; Sontia \& Touyz, 2007). Magnesium, in addition to its antioxidant and anti-inflammatory properties (Weglicki et al., 1996), assists in glucose homeostasis (Ma, Lawson, Liese, Bell, \& Mayer-Davis, 2006; Saris, Mervaala, Karppanen, Khawaja, \& Lewenstam, 2000) and so may help reduce cholesterol and triglycerides (Singh, Rastogi, Sharma, Saharia, \& Kulshretha, 1990), and improve diabetes control.

Importantly, the association between greater dairy food consumption and better cognitive performance remained significant after adjustment for a number of cardiovascular risk factors, including CVD prevalence, hypertension and waist circumference. The strengths of these relationships were modestly attenuated with the addition of these covariates suggesting that they play a role but do not explain entirely associations between dairy food intake and better cognitive functioning.

Several limitations in the present study are acknowledged. Our data are cross-sectional and the dietary questionnaire used has a number of limitations. We were unable to obtain an accurate indication of the quantity of food consumed on each occasion. Participants were asked 'how often do you eat the following foods?', but not questioned as to portion or serving sizes. This undoubtedly limits the accuracy of the estimated intakes of all foods and beverages as quantities are likely to differ substantially amongst individuals as well as the same individual on different occasions. The range of responses to indicate how often a food is consumed was limited in the high intake range. We were therefore unable to determine the specific number of times participants consumed dairy foods beyond 'once or more a day'. Participants in the present study were not required to stipulate the fat content of the dairy food that they consumed (with the exception of milk). We were therefore unable to assess whether fat content was a relevant factor in the associations found, or compare our findings to others who have shown such relationships (Almeida et al., 2006; Eskelinen et al., 2008; Vercambre et al., 2009). The inherent errors involved in the self-reporting of health measures should also be considered. Self-reported nutritional intake can lead to underestimation or overestimation of true associations, and measurement at only one point may not reflect long-term consumption patterns. The age range in the present study was wide, but we adjusted for age in our statistical analytic procedures because we did not have sufficient numbers of subjects to examine results for multiple age groups over a narrower range of ages. 
The present study has a number of strengths. This is the first cross-sectional study that has examined dairy food intake and cognitive performance using a standardized battery of cognitive tests, and controlling for cardiovascular risk factors, in addition to lifestyle and dietary factors. We have examined the relationship between dairy food consumption and cognition in a large, community-based sample, not limited to the elderly. The majority of studies to date exploring relations between dairy food intake and cognition have only used short dementia screening measures, such as the MMSE as indices of cognitive performance. The problems associated with using non-specific global screening tools to measure cognition have been previously discussed (Crichton et al., 2010a). The assessment methods we have used have enabled us to discriminate between effects on different cognitive domains. As we have observed stronger results for some outcome measures than others, the importance of using a thorough cognitive battery has been reinforced.

\section{Conclusions}

In this study, frequent dairy food intake was associated with better cognitive performance. Measurement of dairy food consumption needs to be specific in terms of type, fat content, and quantity of intake. As brain disorders are most likely to impact upon more than a single cognitive ability or behaviour, as in our study, cognitive function needs to be assessed with a thorough neuropsychological test battery measuring a range of cognitive abilities. To enhance our understanding of the possible association between dairy food and cognitive function, longitudinal studies need to be done, with detailed assessments of both diet and cognition at multiple time periods. Ultimately, well-controlled, long-term intervention trials with a sufficient sample size representative of the population are needed.

\section{Acknowledgments}

We thank Amanda L. Goodell and Suzanne Brennan, Maine-Syracuse Longitudinal Study, University of Maine, for their help with data acquisition, and data management. The research was supported by the Maurice de Rohan International Scholarship (University of South Australia), and in part by the National Heart, Lung, and Blood Institute (grants HL67358 and HL81290) and the National Institute on Aging (grant AG03055) of the National Institutes of Health. Conclusions expressed in the paper are those expressed by the authors, not by the institutions providing support.

\section{References}

Akisaki T, Sakurai T, Takata T, Umegaki H, Araki A, Mizuno S, et al. Cognitive dysfunction associates with white matter hyperintensities and subcortical atrophy on magnetic resonance imaging of the elderly diabetes mellitus Japanese elderly diabetes intervention trial (J-EDIT). Diabetes/Metabolism Research and Reviews. 2006; 22:376-384. [PubMed: 16506272]

Alberti KG, Eckel RH, Grundy SM, Zimmet PZ, Cleeman JI, Donato KA, et al. Harmonizing the metabolic syndrome: a joint interim statement of the International Diabetes Federation Task Force on Epidemiology and Prevention; National Heart, Lung, and Blood Institute; American Heart Association; World Heart Federation; International Atherosclerosis Society; and International Association for the Study of Obesity. Circulation. 2009; 120:1640-1645. [PubMed: 19805654]

Almeida OP, Norman P, Hankey G, Jamrozik K, Flicker L. Successful mental health aging: results from a longitudinal study of older Australian men. American Journal of Geriatric Psychiatry. 2006; 14:27-35. [PubMed: 16407579]

Alonso A, Nettleton JA, Ix JH, de Boer IH, Folsom AR, Bidulescu A, et al. Dietary phosphorus, blood pressure, and incidence of hypertension in the atherosclerosis risk in communities study and the multi-ethnic study of atherosclerosis. Hypertension. 2010; 55:776-784. [PubMed: 20083730]

Avila-Funes JA, Garant MP, Aguilar-Navarro S. Relationship between determining factors for depressive symptoms and for dietary habits in older adults in Mexico. Pan American Journal of Public Health. 2006; 19:321-330. [PubMed: 16805974] 
Azadbakht L, Mirmiran P, Esmaillzadeh A, Azizi F. Dairy consumption is inversely associated with the prevalence of the metabolic syndrome in Tehranian adults. American Journal of Clinical Nutrition. 2005a; 82:523-530. [PubMed: 16155263]

Azadbakht L, Mirmiran P, Esmaillzadeh A, Azizi T, Azizi F. Beneficial effects of a dietary approaches to stop hypertension eating plan on features of the metabolic syndrome. Diabetes Care. 2005b; 28:2823-2831. [PubMed: 16306540]

Beydoun MA, Gary TL, Caballero BH, Lawrence RS, Cheskin LJ, Wang Y. Ethnic differences in dairy and related nutrient consumption among US adults and their association with obesity, central obesity, and the metabolic syndrome. American Journal of Clinical Nutrition. 2008; 87:1914-1925. [PubMed: 18541585]

Block G. Foods contributing to energy intake in the US: data from NHANES III and NHANES 1999-2000. Journal of Food Composition and Analysis. 2004; 17:439-447.

Breteler MM, van Amerongen NM, van Swieten JC, Claus JJ, Grobbee DE, van Gijn J, et al. Cognitive correlates of ventricular enlargement and cerebral white matter lesions on magnetic resonance imaging. The Rotterdam study. Stroke. 1994; 25:1109-1115. [PubMed: 8202966]

Bryan J. Mechanisms and evidence for the role of nutrition in cognitive ageing. Ageing International. 2004; 29:28-45.

Choi HK, Willett WC, Stampfer MJ, Rimm E, Hu FB. Dairy consumption and risk of type 2 diabetes mellitus in men: a prospective study. Archives of Internal Medicine. 2005; 165:997-1003. [PubMed: 15883237]

Crichton GE, Bryan J, Murphy KJ, Buckley J. Review of dairy consumption and cognitive performance in adults: findings and methodological issues. Dementia and Geriatric Cognitive Disorders. 2010a; 30:352-361. [PubMed: 20938179]

Crichton GE, Murphy KJ, Bryan J. Dairy intake and cognitive health in middle-aged South Australians. Asia Pacific Journal of Clinical Nutrition. 2010b; 19:161-171. [PubMed: 20460228]

Dore GA, Elias MF, Robbins MA, Budge MM, Elias PK. Relation between central adiposity and cognitive function in the Maine-Syracuse study: attenuation by physical activity. Annals of Behavioral Medicine. 2008; 35:341-350. [PubMed: 18584267]

Elias MF, Beiser A, Wolf PA, Au R, White RF, D'Agostino RB. The preclinical phase of Alzheimer disease: a 22-year prospective study of the Framingham cohort. Archives of Neurology. 2000; 57:808-813. [PubMed: 10867777]

Elias MF, Elias PK, Seliger SL, Narsipur SS, Dore GA, Robbins MA. Chronic kidney disease, creatinine and cognitive functioning. Nephrology Dialysis Transplantation. 2009a; 24:2446-2452.

Elias MF, Elias PK, Sullivan LM, Wolf PA, D'Agostino RB. Lower cognitive function in the presence of obesity and hypertension: the Framing-ham heart study. International Journal of Obesity. 2003; 27:260-268. [PubMed: 12587008]

Elias MF, Elias PK, Sullivan LM, Wolf PA, D'Agostino RB. Obesity, diabetes and cognitive deficit: the Framingham heart study. Neurobiology of Aging. 2005; 26(Suppl. 1):11-16. [PubMed: 16223549]

Elias MF, Robbins MA, Budge MM, Abhayaratna WP, Dore GA, Elias PK. Arterial pulse wave velocity and cognition with advancing age. Hypertension. 2009b; 53:668-673. [PubMed: 19237680]

Elias MF, Robbins MA, Budge MM, Elias PK, Brennan SL, Johnston C, et al. Homocysteine, folate, and vitamins B6 and B12 blood levels in relation to cognitive performance: the Maine-Syracuse study. Psychosomatic Medicine. 2006; 68:547-554. [PubMed: 16868263]

Elias MF, Robbins MA, Budge MM, Elias PK, Dore GA, Brennan SL, et al. Homocysteine and cognitive performance: modification by the ApoE genotype. Neuroscience Letters. 2008; 430:6469. [PubMed: 18023533]

Elwood PC. Time to value milk. International Journal of Epidemiology. 2005; 34:1160-1162. [PubMed: 16027143]

Elwood PC, Pickering JE, Fehily AM. Milk and dairy consumption, diabetes and the metabolic syndrome: the Caerphilly prospective study. Journal of Epidemiology and Community Health. 2007; 61:695-698. [PubMed: 17630368] 
Eskelinen MH, Ngandu T, Helkala EL, Tuomilehto J, Nissinen A, Soininen H, et al. Fat intake at midlife and cognitive impairment later in life: a population-based CAIDE study. International Journal of Geriatric Psychiatry. 2008; 23:741-747. [PubMed: 18188871]

Folstein MF, Folstein SE, McHugh PR. "Mini-mental state". A practical method for grading the cognitive state of patients for the clinician. Journal of Psychiatric Research. 1975; 12:189-198. [PubMed: 1202204]

French SA, Lin BH, Guthrie JF. National trends in soft drink consumption among children and adolescents age 6 to 17 years: prevalence, amounts, and sources, 1977/1978 to 1994/1888. Journal of the American Dietetic Association. 2003; 103:1326-1331. [PubMed: 14520252]

Harnack L, Stang J, Story M. Soft drink consumption among US children and adolescents: nutritional consequences. Journal of the American Dietetic Association. 1999; 99:436-441. [PubMed: 10207395]

Kaaks R, Riboli E. Validation and calibration of dietary intake measurements in the EPIC project: methodological considerations. European prospective investigation into cancer and nutrition. International Journal of Epidemiology. 1997; 26(Suppl. 1):S15-S25. [PubMed: 9126530]

Laitinen MH, Ngandu T, Rovio S, Helkala EL, Uusitalo U, Viitanen M, et al. Fat intake at midlife and risk of dementia and Alzheimer's disease: a population-based study. Dementia and Geriatric Cognitive Disorders. 2006; 22:99-107. [PubMed: 16710090]

Lee L, Kang SA, Lee HO, Lee BH, Park JS, Kim JH, et al. Relationships between dietary intake and cognitive function level in Korean elderly people. Public Health. 2001; 115:133-138. [PubMed: 11406779]

Lezak, MD.; Howieson, DB.; Loring, DW. Neuropsychological assessment. 4th ed.. Oxford University Press; New York, NY, USA: 2004.

Liu S, Choi HK, Ford E, Song Y, Klevak A, Buring JE, et al. A prospective study of dairy intake and the risk of type 2 diabetes in women. Diabetes Care. 2006; 29:1579-1584. [PubMed: 16801582]

Luhovyy BL, Akhavan T, Anderson H. Whey proteins in the regulation of food intake and satiety. Journal of the American College of Nutrition. 2007; 26:704S-712S. [PubMed: 18187437]

Lutsey PL, Steffen LM, Stevens J. Dietary intake and the development of the metabolic syndrome. The atherosclerosis risk in communities study. Circulation. 2008; 117:754-761. [PubMed: 18212291]

Ma B, Lawson AB, Liese AD, Bell RA, Mayer-Davis EJ. Dairy, magnesium, and calcium intake in relation to insulin sensitivity: approaches to modeling a dose-dependent association. American Journal of Epidemiology. 2006; 164:449-458. [PubMed: 16861328]

Major GC, Chaput JP, Ledoux M, St-Pierre S, Anderson GH, Zemel MB, et al. Recent developments in calcium-related obesity research. Obesity Reviews. 2008; 9:428-445. [PubMed: 18282178]

McKhann G, Drachman D, Folstein M, Katzman R, Price D, Stadlan EM. Clinical diagnosis of Alzheimer's disease: report of the NINCDS-ADRDA Work Group under the auspices of Department of Health and Human Services task force on Alzheimer's disease. Neurology. 1984; 34:939-944. [PubMed: 6610841]

Mennen LI, Lafay L, Feskens EJM, Novak M, Lepinay P, Balkau B. Possible protective effect of bread and dairy products on the risk of metabolic syndrome. Nutrition Research. 2000; 20:335-347.

Pereira MA, Jacobs DR Jr. Van Horn L, Slattery ML, Kartashov AI, Ludwig DS. Dairy consumption, obesity, and the insulin resistance syndrome in young adults: the CARDIA study. Journal of the American Medical Association. 2002; 287:2081-2089. [PubMed: 11966382]

Rabbitt P, Mogapi O, Scott M, Thacker N, Lowe C, Horan M, et al. Effects of global atrophy, white matter lesions, and cerebral blood flow on age-related changes in speed, memory, intelligence, vocabulary, and frontal function. Neuropsychology. 2007; 21:684-695. [PubMed: 17983282]

Radloff LS. The CES-D scale: a self-report depression scale for research in the general population. Applied Psychological Measures. 1977; 1:385-401.

Rahman A, Sawyer Baker P, Allman RM, Zamrini E. Dietary factors and cognitive impairment in community-dwelling elderly. Journal of Nutrition, Health and Aging. 2007; 11:49-54.

Rampersaud GC, Bailey LB, Kauwell GPA. National survey beverage consumption data for children and adolescents indicate the need to encourage a shift toward more nutritive beverages. Journal of the American Dietetic Association. 2003; 103:97-100. [PubMed: 12525800] 
Riboli E, Kaaks R. The EPIC project: rationale and study design. European prospective investigation into cancer and nutrition. International Journal of Epidemiology. 1997; 26(Suppl. 1):S6-14. [PubMed: 9126529]

Robbins MA, Elias MF, Elias PK, Budge MM. Blood pressure and cognitive function in an AfricanAmerican and a Caucasian-American sample: the Maine-Syracuse study. Psychosomatic Medicine. 2005; 67:707-714. [PubMed: 16204428]

Saris NE, Mervaala E, Karppanen H, Khawaja JA, Lewenstam A. Magnesium. An update on physiological, clinical and analytical aspects. Clinica Chimica Acta. 2000; 294:1-26.

Singh RB, Rastogi SS, Sharma VK, Saharia RB, Kulshretha SK. Can dietary magnesium modulate lipoprotein metabolism? Magnesium and Trace Elements. 1990; 9:255-264. [PubMed: 2130823]

Soderlund H, Nilsson LG, Berger K, Breteler MM, Dufouil C, Fuhrer R, et al. Cerebral changes on MRI and cognitive function: the CASCADE study. Neurobiology of Aging. 2006; 27:16-23. [PubMed: 16298236]

Solfrizzi V, Panza F, Capurso A. The role of diet in cognitive decline. Journal of Neural Transmission. 2003; 110:95-110. [PubMed: 12541015]

Sontia B, Touyz RM. Role of magnesium in hypertension. Archives of Biochemistry and Biophysics. 2007; 458:33-39. [PubMed: 16762312]

Steffen LM, Kroenke CH, Yu X, Pereira MA, Slattery ML, Van Horn L, et al. Associations of plant food, dairy product, and meat intakes with 15-y incidence of elevated blood pressure in young black and white adults: the coronary artery risk development in young adults (CARDIA) Study. American Journal of Clinical Nutrition. 2005; 82:1169-1177. [PubMed: 16332648]

Teegarden D. The influence of dairy product consumption on body composition. The Journal of Nutrition. 2005; 135:2749-2752. [PubMed: 16317115]

Teegarden D, Donkin SS. Vitamin D: emerging new roles in insulin sensitivity. Nutrition Research Reviews. 2009; 22:82-92. [PubMed: 19555519]

Tiehuis AM, Vincken KL, van den Berg E, Hendrikse J, Manschot SM, Mali WP, et al. Cerebral perfusion in relation to cognitive function and type 2 diabetes. Diabetologia. 2008; 51:1321-1326. [PubMed: 18488188]

United States Department of Agriculture. [17.04.11] MyPyramid.Gov. 2011. Online. Available HTTP: <http://www.mypyramid.gov/>

van den Berg E, Kloppenborg RP, Kessels RP, Kappelle LJ, Biessels GJ. Type 2 diabetes mellitus, hypertension, dyslipidemia and obesity: a systematic comparison of their impact on cognition. International Journal of Biochemistry, Biophysics and Molecular Biology. 2009; 1792:470-481.

Vercambre MN, Boutron-Ruault MC, Ritchie K, Clavel-Chapelon F, Berr C. Long-term association of food and nutrient intakes with cognitive and functional decline: a 13-year follow-up study of elderly French women. British Journal of Nutrition. 2009; 102:419-427. [PubMed: 19203415]

Verdelho A, Madureira S, Ferro JM, Basile AM, Chabriat H, Erkinjuntti T, et al. Differential impact of cerebral white matter changes, diabetes, hypertension and stroke on cognitive performance among non-disabled elderly. The LADIS study. Journal of Neurology, Neurosurgery and Psychiatry. 2007; 78:1325-1330.

von Hurst PR, Stonehouse W, Coad J. Vitamin D supplementation reduces insulin resistance in South Asian women living in New Zealand who are insulin resistant and vitamin D deficient e a randomised, placebo-controlled trial. British Journal of Nutrition. 2010; 103:549-555. [PubMed: 19781131]

Waldstein, SR.; Elias, MF., editors. Neuropsychology of cardiovascular disease. Lawrence Erlbaum Associates; Mahwah, NJ, USA: 2001.

Wang L, Manson JE, Buring JE, Lee IM, Sesso HD. Dietary intake of dairy products, calcium, and vitamin D and the risk of hypertension in middle-aged and older women. Hypertension. 2008; 51:1073-1079. [PubMed: 18259007]

Weglicki WB, Makf IT, Kramer JH, Dickens BF, Cassidy MM, Stafford RE, et al. Role of free radicals and substance $\mathrm{P}$ in magnesium deficiency. Cardiovascular Research. 1996; 31:677-682. [PubMed: 9138860] 
Wolf AM, Hunter DJ, Colditz GA, Manson JE, Stampfer MJ, Corsano KA, et al. Reproducibility and validity of a self-administered physical-activity questionnaire. International Journal of Epidemiology. 1994; 23:991-999. [PubMed: 7860180]

Wright CB, Festa JR, Paik MC, Schmiedigen A, Brown TR, Yoshita M, et al. White matter hyperintensities and subclinical infarction: associations with psychomotor speed and cognitive flexibility. Stroke. 2008; 39:800-805. [PubMed: 18258844]

Yamada M, Kasagi F, Sasaki H, Masunari N, Mimori Y, Suzuki G. Association between dementia and midlife risk factors: the Radiation Effects Research Foundation adult health study. Journal of the American Geriatrics Society. 2003; 51:410-414. [PubMed: 12588587]

Zemel MB. Role of calcium and dairy products in energy partitioning and weight management. American Journal of Clinical Nutrition. 2004; 79:907S-912S. [PubMed: 15113738]

Zemel MB. The role of dairy foods in weight management. Journal of the American College of Nutrition. 2005; 24:537S-546S. [PubMed: 16373953]

Zemel MB, Teegarden D, Van Loan MD, Schoeller DA, Matkovic V, Lyle RM, et al. Dairy-rich diets augment fat loss on an energy-restricted diet: a multicenter trial. Nutrients. 2009; 1:83-100. [PubMed: 22253969] 


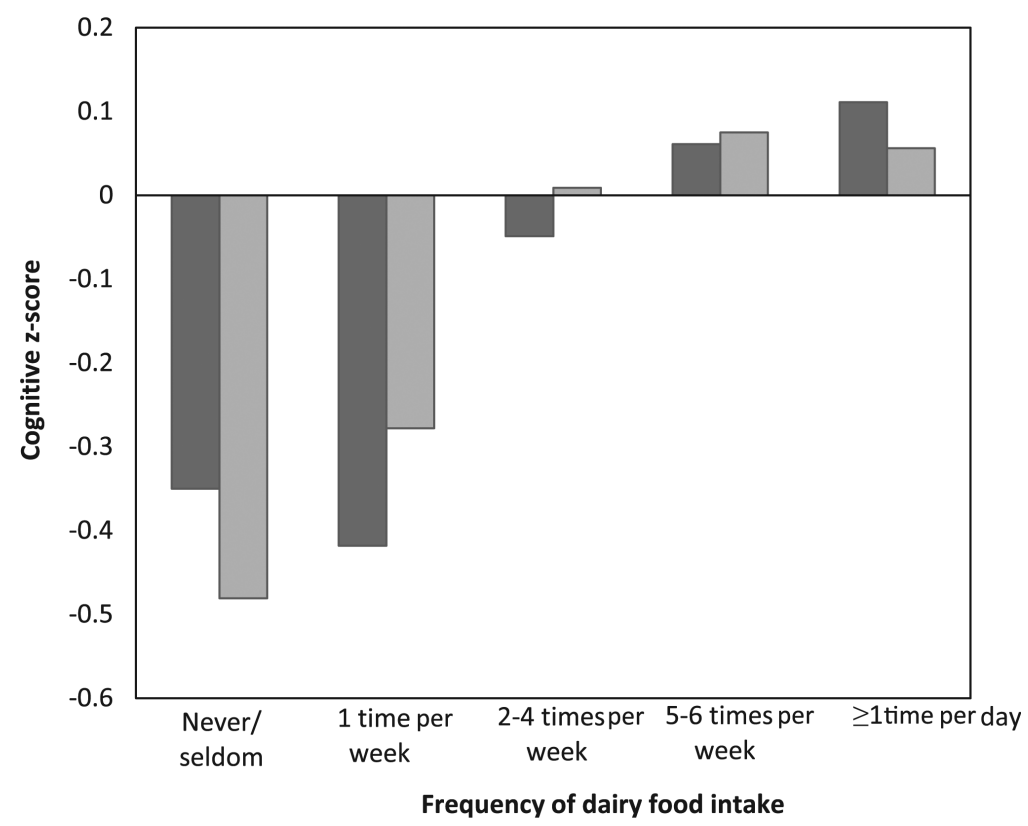

Fig. 1.

Cognitive $z$-scores for the global composite $(\square)$ and Mini-Mental State Examination $(\square)$ for participants across increasing dairy food intake categories, ranging from never/seldom, to at least one time per day. 


\section{Table 1}

Description of the Maine-Syracuse Longitudinal Study neuropsychological test battery: cognitive composites, included cognitive tests grouped according to factor analyses, and abilities assessed.

\begin{tabular}{|c|c|c|}
\hline Cognitive domain & Tests included in domain & Cognitive ability measured \\
\hline Global composite & & $\begin{array}{l}\text { Global composite of cognitive performance including all } \\
\text { domains }\end{array}$ \\
\hline Verbal episodic memory & $\begin{array}{l}\text { Logical memory immediate recall }^{a} \\
\text { Logical memory delayed recall }^{a} \\
\text { Hopkins Verbal Learning Test }\end{array}$ & $\begin{array}{l}\text { Immediate memory, verbal recall } \\
\text { Delayed memory, verbal recall } \\
\text { Verbal learning and memory }\end{array}$ \\
\hline $\begin{array}{l}\text { Visual-spatial memory and } \\
\text { organization }\end{array}$ & $\begin{array}{l}\text { Block design }{ }^{c} \\
\text { Object assembly } \\
\text { Visual reproductions immediate }^{c} \\
\text { recall }^{a} \\
\text { Visual reproductions delayed recall }^{a} \\
\text { Matrix reasoning }^{b} \\
\text { Hooper visual organization }\end{array}$ & $\begin{array}{l}\text { Visual—spatial perception, organization and construction } \\
\text { Speed of visual—spatial organization } \\
\text { Immediate recall, visual memory, visual—spatial problem } \\
\text { solving } \\
\text { Delayed recall, visual memory, visual—spatial problem solving } \\
\text { Abstract reasoning, pattern recognition } \\
\text { Visual—spatial organization, some demands on executive } \\
\text { function }\end{array}$ \\
\hline Scanning and tracking & $\begin{array}{l}\text { Trail making } \mathrm{A}^{d} \\
\text { Trail making B } \\
\text { Digit symbol substitution } \\
\text { Symbol search }^{b}\end{array}$ & $\begin{array}{l}\text { Visual scanning and tracking, concentration and attention } \\
\text { Complex visual scanning and tracking, executive function } \\
\text { Psychomotor performance } \\
\text { Visual processing speed }\end{array}$ \\
\hline Working memory & $\begin{array}{l}\text { Digit span forward }{ }^{c} \\
\text { Digit span backward } c \\
\text { Letter-number sequence } b \\
\text { Controlled oral word associations }\end{array}$ & $\begin{array}{l}\text { Attention, concentration } \\
\text { Attention, concentration, working memory } \\
\text { Working memory } \\
\text { Verbal fluency, executive function }\end{array}$ \\
\hline Executive function & $\begin{array}{l}\text { Trail making test } \mathrm{B}^{d} \\
\text { Controlled oral word associations }\end{array}$ & $\begin{array}{l}\text { Complex visual scanning and tracking, executive function } \\
\text { Verbal fluency, executive function }\end{array}$ \\
\hline Similarities $^{c}$ & - & Verbal intelligence, abstract reasoning \\
\hline Mini-mental state examination & - & Global cognitive screening \\
\hline
\end{tabular}


Table 2

Self-reported intakes of cheese, yoghurt/dairy desserts, cream/ice-cream, total dairy food, and milk.

\begin{tabular}{|c|c|c|c|c|c|}
\hline \multirow[t]{3}{*}{ Dairy product } & \multicolumn{5}{|l|}{ Dairy food intake } \\
\hline & Never/seldom & 1 Time per week & $\underline{\text { 2-4 Times per week }}$ & 5-6 Times per week & $\underline{1}$ Times per day \\
\hline & $n(\%)$ & $n(\%)$ & $n(\%)$ & $n(\%)$ & $n(\%)$ \\
\hline Cheese & $167(17.2)$ & $223(22.9)$ & $429(44.1)$ & $102(10.5)$ & $51(5.2)$ \\
\hline Yoghurt and dairy desserts & $533(54.8)$ & $155(15.9)$ & $185(19.0)$ & $63(6.5)$ & $36(3.7)$ \\
\hline Cream and ice-cream & $460(47.3)$ & $260(26.7)$ & $185(19.0)$ & $53(5.5)$ & $14(1.4)$ \\
\hline \multirow[t]{2}{*}{ Total dairy food } & $43(4.4)$ & $55(5.7)$ & $248(25.5)$ & $262(27.0)$ & $364(37.4)$ \\
\hline & $0-150 \mathrm{~mL} \mathrm{day}^{-1}$ & $150 \mathrm{~mL}^{\text {day }^{-1}}$ & $300 \mathrm{~mL} \mathrm{day}^{-1}$ & $450 \mathrm{~mL} \mathrm{day}^{-1}$ & $>600 \mathrm{~mL} \mathrm{day}^{-1}$ \\
\hline Milk & $328(33.7)$ & $115(11.8)$ & $205(21.1)$ & $65(6.7)$ & $259(26.6)$ \\
\hline Whole fat ${ }^{a}(7 \%)$ & $27(41.5)$ & $9(13.8)$ & $15(23.1)$ & $1(1.5)$ & $13(20.0)$ \\
\hline Skim/reduced fat ${ }^{a}(80 \%)$ & $230(31.2)$ & $92(12.5)$ & $143(19.4)$ & $55(7.5)$ & $217(29.4)$ \\
\hline Other (e.g., soy) ${ }^{a}(13 \%)$ & $45(37.5)$ & $14(11.7)$ & $28(23.3)$ & $9(7.5)$ & $24(20.0)$ \\
\hline
\end{tabular}

$a_{\%}$ From within milk group. 
Table 3

Demographic, health and dietary characteristics of sample, comparing those who consume dairy food at least once per day with those who consume less than this. ${ }^{a}$

\begin{tabular}{|c|c|c|c|c|c|c|}
\hline \multirow[t]{2}{*}{ Parameter } & \multicolumn{2}{|c|}{ Dairy food $<1$ time per day $(n=608)$} & \multicolumn{3}{|c|}{ Dairy food at least 1 time per day $(n=364)$} & \multirow{2}{*}{$p^{*}$} \\
\hline & $M$ & SD & $M$ & SD & & \\
\hline Age (years) & 61.99 & 12.74 & 62.10 & 13.01 & & NS \\
\hline Education & 14.42 & 2.67 & 15.03 & 2.75 & & .001 \\
\hline Physical activity (MET hours per week) & 17.88 & 24.04 & 21.84 & 33.53 & & NS \\
\hline Smoking (cigarettes per week) & 11.23 & 41.68 & 6.27 & 27.13 & & .043 \\
\hline Waist circumference $(\mathrm{cm})$ & 96.26 & 14.72 & 93.74 & 15.47 & & .012 \\
\hline BMI $\left(\mathrm{kg} \mathrm{m}^{-2}\right)$ & 29.46 & 5.85 & 29.05 & 6.13 & & NS \\
\hline Total cholesterol $\left(\mathrm{mmol} \mathrm{L}^{-1}\right)$ & 5.21 & 1.04 & 5.23 & 1.03 & & NS \\
\hline HDL cholesterol $\left(\mathrm{mmol} \mathrm{L}^{-1}\right)$ & 1.38 & .40 & 1.40 & .39 & & NS \\
\hline LDL cholesterol $\left(\mathrm{mmol} \mathrm{L}^{-1}\right)$ & 3.12 & .88 & 3.12 & .082 & & NS \\
\hline Triglycerides $\left(\mathrm{mmol} \mathrm{L}^{-1}\right)$ & 1.62 & 1.22 & 1.61 & 1.35 & & NS \\
\hline Systolic BP (mmHg) & 131.26 & 21.63 & 130.18 & 21.65 & & NS \\
\hline Diastolic BP (mmHg) & 71.00 & 9.99 & 69.54 & 10.06 & & .028 \\
\hline Depression (CES-D) ${ }^{b}$ & 8.08 & 7.31 & 6.74 & 6.02 & & .004 \\
\hline Folic acid (ng dL ${ }^{-1}$ ) & 14.89 & 5.39 & 16.15 & 5.42 & & .001 \\
\hline Homocysteine $\left(\mu \mathrm{mol} \mathrm{L}^{-1}\right)$ & 10.22 & 3.98 & 9.47 & 3.62 & & .002 \\
\hline \multirow[t]{2}{*}{ Glucose $\left(\mathrm{mmol} \mathrm{L}^{-1}\right)$} & 5.55 & 1.69 & 5.42 & 1.38 & & NS \\
\hline & $n$ & $\%$ (of Total) & $n$ & $\%$ (of & Cotal) & $p^{* *}$ \\
\hline \multicolumn{7}{|l|}{ Gender } \\
\hline Males & 258 & 34.7 & 137 & & 65.3 & NS \\
\hline Females & 342 & 60.1 & 227 & & 39.9 & NS \\
\hline $\mathrm{CVD}^{c}$ & 98 & 10.1 & 41 & & 4.2 & .036 \\
\hline Diabetes $^{d}$ & 75 & 7.7 & 46 & & 4.7 & NS \\
\hline Hypertension $^{e}$ & 389 & 40.0 & 209 & & 21.5 & .042 \\
\hline Metabolic syndrome $^{f}$ & 280 & 28.8 & 152 & & 15.6 & NS \\
\hline Anti-hypertensive medication & 313 & 32.2 & 171 & & 17.6 & NS \\
\hline Cholesterol medication & 174 & 17.9 & 92 & & 9.5 & NS \\
\hline \multirow[t]{2}{*}{ Diabetes medication } & 62 & 6.4 & 39 & & 4.0 & NS \\
\hline & $M$ & SEM & $M$ & SEM & & $p^{* * *}$ \\
\hline Grains per day & 3.90 & .059 & 3.51 & .076 & & .000 \\
\hline Fruit per day & 1.61 & .037 & 1.63 & .048 & & NS \\
\hline Vegetables per day & 2.65 & .042 & 2.86 & .055 & & .004 \\
\hline Protein foods per day & 2.01 & .031 & 2.07 & .041 & & NS \\
\hline Other (fats/sweets) per day & 2.72 & .071 & 2.11 & .092 & & .000 \\
\hline Total all foods serves per day ${ }^{g}$ & 14.09 & 4.59 & 16.02 & 4.36 & & .000 \\
\hline
\end{tabular}




\begin{tabular}{lllllll}
\hline Parameter & \multicolumn{2}{l}{ Dairy food < 1 time per day $(\boldsymbol{n = 6 0 8})$} & \multicolumn{2}{l}{ Dairy food at least 1 time per day $(\boldsymbol{n}=\mathbf{3 6 4})$} & $\boldsymbol{p}^{*}$ \\
\cline { 2 - 6 } & $\boldsymbol{M}$ & SD & $\boldsymbol{M}$ & SD & \\
\hline Alcohol (g per week) & 39.48 & 2.80 & 30.22 & 3.64 & .046 \\
\hline
\end{tabular}

${ }^{a}$ Abbreviations are: BMI, body mass index; BP, blood pressure; CES-D, Centre for Epidemiologic Studies Depression Scale; CVD, cardiovascular disease; HDL, high-density lipoprotein; LDL, low-density lipoprotein; MET, metabolic equivalent; SD, standard deviation; SEM, standard error of the mean. Statistical analyses are:

analysis of variance for continuous variables

**

chi square for categorical variables

***

analysis of covariance, controlling for total serves per day all food groups.

${ }^{b}$ CES-D: higher score indicates greater number of depressive symptoms (Radloff, 1977).

${ }^{c}$ CVD was defined as present if there was self-reported history of coronary artery disease, myocardial infarction, congestive heart failure, transient ischaemic attack, or angina pectoris.

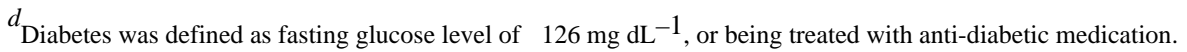

${ }^{e}$ Hypertension was defined as a BP $\geq 140 / 90 \mathrm{mmHg}$ or active treatment for hypertension.

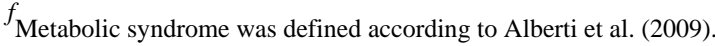

$g_{\text {Mean and SD }}$ 


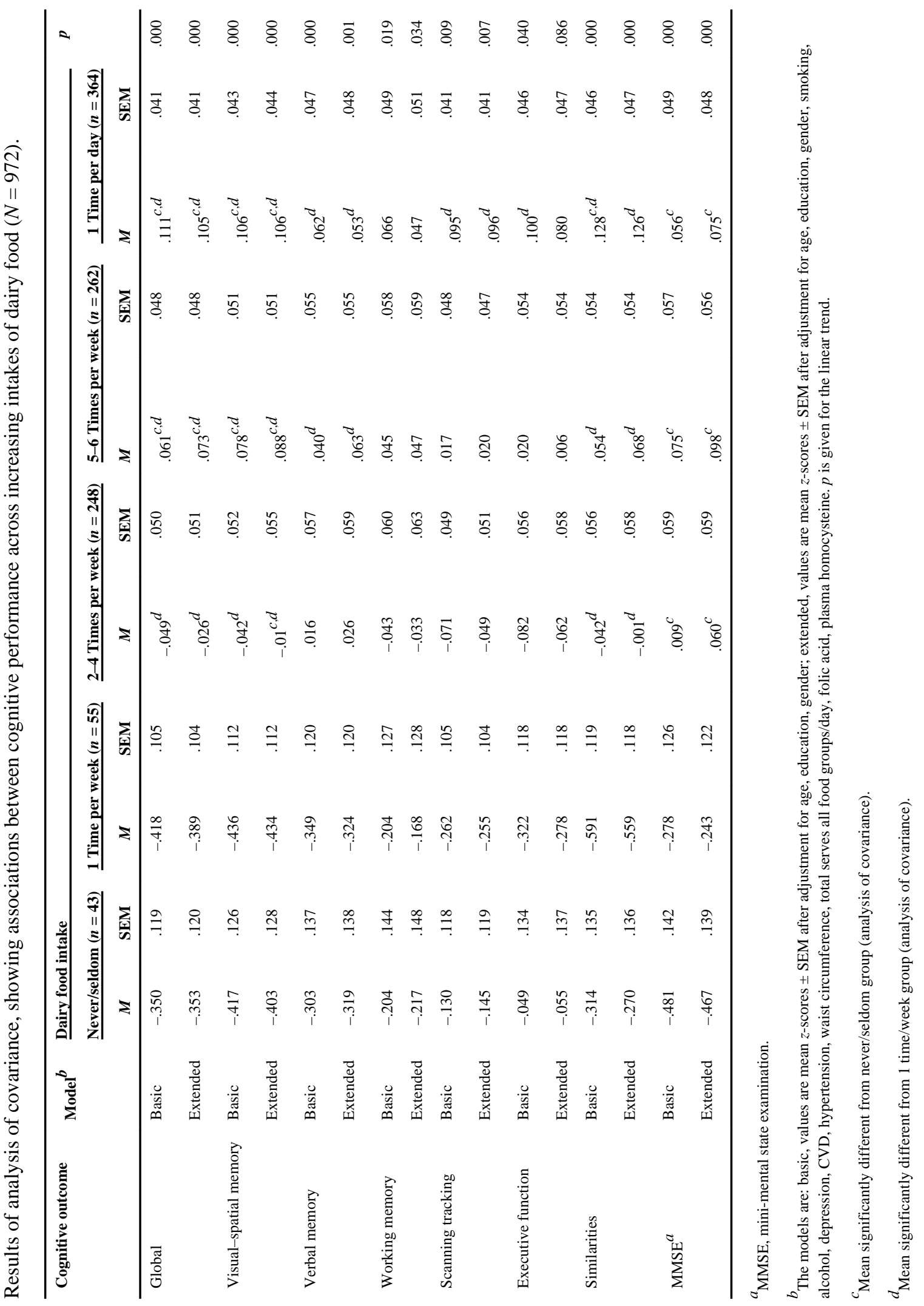


Table 5

Logistic regression analysis showing odds ratios (OR) and associated 95\% confidence intervals (CI) for performing in the lowest quartile of cognitive scores for persons with different dairy food intakes (never/ seldom eat dairy food is the reference group) and $p$ values for differences between groups.

\begin{tabular}{|c|c|c|c|c|c|c|}
\hline \multirow[t]{2}{*}{ Cognitive outcome } & \multicolumn{3}{|c|}{$\underline{B a s i c}$ model ${ }^{a}$} & \multicolumn{3}{|c|}{$\underline{\text { Extended model }^{b}}$} \\
\hline & OR & 95\% CI & $p$ & OR & $95 \%$ CI & $p$ \\
\hline \multicolumn{7}{|l|}{ Global } \\
\hline 1 Time per week & .56 & $.22,1.40$ & .212 & .60 & $.23,1.58$ & .301 \\
\hline 2-4 Times per week & .27 & $.13, .57$ & .001 & .29 & $.13, .64$ & .002 \\
\hline 5-6 Times per week & .19 & $.09, .40$ & .000 & .20 & $.09, .45$ & .000 \\
\hline$\geq 1$ Time per day & .13 & $.06, .28$ & .000 & .15 & $.07, .34$ & .000 \\
\hline \multicolumn{7}{|l|}{ Visual-spatial memory } \\
\hline 1 Time per week & .89 & $.35,2.23$ & .795 & .96 & $.37,2.53$ & .937 \\
\hline 2-4 Times per week & .49 & $.23,1.04$ & .063 & .51 & $.23,1.14$ & .100 \\
\hline 5-6 Times per week & .40 & $.19, .85$ & .017 & .44 & $.19, .98$ & .044 \\
\hline$\geq 1$ Time per day & .30 & $.14, .63$ & .002 & .34 & $.15, .77$ & .009 \\
\hline \multicolumn{7}{|l|}{ Verbal memory } \\
\hline 1 Time per week & 1.45 & $.61,3.45$ & .405 & 1.35 & $.54,3.38$ & .520 \\
\hline 2-4 Times per week & .67 & $.33,1.38$ & .275 & .61 & $.29,1.33$ & .215 \\
\hline 5-6 Times per week & .54 & $.26,1.12$ & .098 & .48 & $.22,1.05$ & .064 \\
\hline$\geq 1$ Time per day & .52 & $.25,1.06$ & .071 & .50 & $.23,1.09$ & .082 \\
\hline \multicolumn{7}{|l|}{ Working memory } \\
\hline 1 Time per week & .69 & $.30,1.62$ & .396 & .61 & $.25,1.49$ & .277 \\
\hline 2-4 Times per week & .42 & $.21, .84$ & .014 & .36 & $.17, .74$ & .006 \\
\hline 5-6 Times per week & .39 & $.19, .78$ & .007 & .36 & $.17, .75$ & .006 \\
\hline$\geq 1$ Time per day & .31 & $.15, .61$ & .001 & .28 & $.13, .58$ & .001 \\
\hline \multicolumn{7}{|l|}{ Scanning tracking } \\
\hline 1 Time per week & 1.61 & $.59,4.41$ & .355 & 1.37 & $.48,3.96$ & .557 \\
\hline 2-4 Times per week & .82 & $.36,1.88$ & .634 & .67 & $.28,1.61$ & .374 \\
\hline 5-6 Times per week & .91 & $.39,2.09$ & .819 & .84 & $.35,2.01$ & .688 \\
\hline$\geq 1$ Time per day & .62 & $.27,1.41$ & .253 & .55 & $.23,1.31$ & .176 \\
\hline \multicolumn{7}{|l|}{ Executive function } \\
\hline 1 Time per week & .92 & $.37,2.25$ & .849 & .82 & $.32,2.09$ & .683 \\
\hline 2-4 Times per week & .48 & $.23, .99$ & .049 & .41 & $.19, .87$ & .021 \\
\hline 5-6 Times per week & .38 & $.18, .80$ & .011 & .36 & $.17, .79$ & .010 \\
\hline$\geq 1$ Time per day & .41 & $.20, .85$ & .017 & .39 & $.18, .85$ & .017 \\
\hline \multicolumn{7}{|l|}{ Similarities } \\
\hline 1 Time per week & 1.28 & $.54,3.07$ & .575 & 1.31 & $.52,3.30$ & .565 \\
\hline 2-4 Times per week & .42 & $.20, .87$ & .019 & .41 & $.19, .90$ & .026 \\
\hline 5-6 Times per week & .35 & $.17, .73$ & .005 & .33 & $.15, .73$ & .006 \\
\hline$\geq 1$ Time per day & .27 & $.13, .55$ & .000 & .27 & $.12, .60$ & .001 \\
\hline
\end{tabular}

MMSE 


\begin{tabular}{|c|c|c|c|c|c|c|}
\hline \multirow[t]{2}{*}{ Cognitive outcome } & \multicolumn{3}{|c|}{$\underline{B a s i c}$ model $^{a}$} & \multicolumn{3}{|c|}{$\underline{\text { Extended model }} b$} \\
\hline & OR & $95 \% \mathrm{CI}$ & $p$ & OR & $95 \% \mathrm{CI}$ & $p$ \\
\hline 1 Time per week & .49 & $.21,1.18$ & .113 & .50 & $.19,1.28$ & .147 \\
\hline 2-4 Times per week & .47 & $.24, .95$ & .035 & .44 & $.21, .94$ & .033 \\
\hline 5-6 Times per week & .40 & $.20, .80$ & .010 & .42 & $.20, .90$ & .026 \\
\hline$\geq 1$ Time per day & .33 & $.17, .66$ & .002 & .35 & $.16, .75$ & .007 \\
\hline
\end{tabular}

${ }^{a}$ Basic model: age, education, gender.

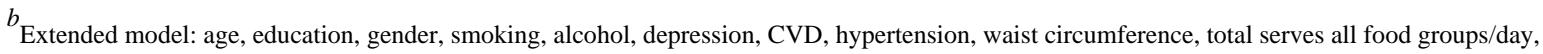
folic acid, plasma homocysteine. 